\title{
Influence of Top Leadership on Procurement Management in Technical Universities, Ghana
}

\author{
David Asante* Helena Mary Boakye \\ Faculty of Business Studies, Takoradi Technical University, PO box 256, Takoradi, Ghana
}

\begin{abstract}
This study examines the influence of top leadership on procurement management at the Ghana technical Universities. Purposive- random sampling was employed to select 25 respondents on which structured questionnaires were administered and analyzed using Correlation and linear regression Analysis. The study found that top leadership has a significant negative influence on procurement management responsiveness, which calls for attention. This influence is very strong as justified by Pearson's correlation coefficient ${ }^{\circledR}=0.884$ with a Pvalue $=0.001$. Top leadership at the Ghana technical Universities seems interfering procurement activities than making it responsive, and this can result in compromising professionalism in procurement management to trigger consistent losses or fund misappropriations in effect. The study recommends that Ghana Education Service and/or stakeholder authorities offer intensive moral and ethical training programs to top leaders of various institutions aside laying down some deterrents against such interferences.
\end{abstract}

Keywords: Leadership, Procurement, Technical Universities, Ghana

DOI: $10.7176 / \mathrm{EJBM} / 11-25-11$

Publication date:September $30^{\text {th }} 2019$

\subsection{Introduction}

Many organizations fail to capture billions of dollars in procurement savings because they lack the leadership skills, processes, and infrastructure to effectively manage procurement across all spending categories (Minahan, 2004). Effective implementation of procurement strategies - after a baseline spend analysis - depends largely on an organization's supporting structure, systems, processes, policies, and performance measures.

The rising and expanding influence of purchasing in leading organizations is apparent. A sixteen year longitudinal survey of large north American supply organizations revealed that purchasing has grown substantially in corporate status and influence since 1987 (Johnson et al, 2006). An example of this is Procter \& gamble (P\&g), a best-in-class company that views purchasing as one of its core capability areas (Rudzki et al. 2005). At P\&g, the global supply manager has tremendous influence over the organization in that he or she oversees not only purchasing but manufacturing, engineering, and other operational functions as well (Rudzki et al. 2005). Managing organizational spend while enforcing proper procurement policies is always a constant concern for procurement leaders and that's a tip of the procurement challenge iceberg needing much focus, attention and some independence.

Experts emphasize that the head (chief) procurement officer should be no more than one level removed from the chief executive officer i.e. to properly position procurement within the organization and ensure its ability to contribute strategically. A direct reporting relationship between the two positions is not necessary, but regular communication and access is (Rudzki et al. 2005). This is to ensure effective coordination in all procurement activities.

Today organizations are moving toward center-led procurement or purchasing operations, though not necessarily a centralized organizational structure. Most procurement experts believe that 15 to 20 percent of purchased materials and services, translating into billions of dollars in a large organization, can be 'saved' by centralizing procurement and leveraging organizations' buying power (Richter 200). Reflecting the experts' notion, Aberdeen's survey and interview of procurement executives at 100 global enterprises show that best-in-class organizations that have transitioned to a center-led procurement operation and concentrated spend under purchasing management show significant improvements in many areas (Minahan 2005). improvements include leveraged spending and negotiating power; standardized purchasing procedures; decreased percentage of maverick, or off-contract, spending (AberdeenGroup 2005a; Minahan 2005); and improved market intelligence and costing measures (AberdeenGroup 2005a). Despite reports of success stories, many medium and large institutions maintain decentralized, splintered, and uncoordinated procurement operations (Richter 200). Decentralized purchasing operations have a negative effect on purchasing performance in a number of ways. For instance, a decentralized operation increases supplier proliferation and, in many cases, places one business unit in competition with another for the same supplier's work. Moreover, a decentralized operation makes it difficult to track and gather information for spend analysis, thereby preventing firms from recognizing redundant and over-specified purchases (nelson et al. 2005). A well-disciplined and effective leadership plays key role to achieving decent flow in either purchasing operations.

Leadership is important in the procurement context since, within an organization, procurement touches so many parts of the overall organizational operation. One can learn almost everything about an organization by 
watching what it needs, what it wants, what it buys, when it buys, how it buys and what it does with what it buys. Conversely, poor purchasing performance translates into poor performance by the organization overall. Money wasted on bad procurement decisions and process destroys organizational effectiveness. Thus, the importance of leadership and procurement is difficult to exaggerate.

\subsection{Statement of the problem}

According to Amayi and Ngugi's (2013) research on factors influencing procurement performance, leadership and management support is positively correlated with organizational performance. Oyuke and Shale (2014) also studied the relationship between management support and organizational performance revealing that indeed organizational performance receives a major boost whenever there is leadership and management support. However, a research by Kalubanga (2012) shows that managerial support can be a barrier to organizational performance particularly when members of the management pursues personal interests rather than supporting organizational performance. The recent study of Walter and George (2017) explains that top management is charged with responsibility of formulating policies, vision and goals of the organization; ensuring that employees are committed to organizational goals; provide guidance to support staff and providing direction to the entire organization therefore, for procurement initiatives to be successful, they must enjoy support of leadership and management. There is a conflicting idea on the exact impact or influence top leaders have on corporate procurement management. The phenomenon needs particular attention in Ghana following recent occurrences at the technical universities. A typical example was the alleged Scandal at Ho Technical University involving management - over charges including procurement breaches and misappropriation (Daily Guide, 2018). Proponents believe that procurement managers are highly influenced by top executives of the institutions when going through the procurement process. This does not give enough room for procurement officers to exhibit much professionalism in their duties therefore; the stated scandal is vindicated, anecdotally. However, enough evidence is needed in this claim. The present paper investigates the influence of top leadership role on procurement management in Technical Universities, Ghana.

\subsection{Significance of the study}

Finding of this study is useful not only to procurement management at technical universities in Ghana, but also professionals within procurement field as well as top hierarchy leaders in organizations. Conclusion of this paper suggests how useful top leaders should rather be in procurement management processes i.e holding off all personal interests. Posterity researchers and scholars can then make use of this finding to gain better understanding of the phenomenon under study "influence of top leadership on procurement management".

\subsection{Literature Review}

\subsection{Theoretical Review}

According to Chari et al (2016) leadership and management support influence all aspects of procurement performance ranging from establishing new systems, green procurement as well as improving levels of transparency. Lack of leadership and management support has been responsible for failure of many procurement initiatives because top management approves funding for specific procurement initiatives. Kemunto and Ngugi (2014) added that leadership and management support play critical role in enhancing organizational performance. The scholars believe both support collaborative relationships between a company and its suppliers, facilitating transparent negotiations and long term relationships that eventually lead to procurement of high quality inputs at affordable prices. Mose et al. (2013) opine that for any procurement initative to be successful, it must enjoy full management support. The top management is therefore required to give appropriate support and attention to procurement in order to bring forth improved organizational performance. Amemba et al. (2013) also supports the above views that top management support for collaborative relationships between the buyers and suppliers is essential for enhancing organizational performance. Mohamad and Abdulrahman (2018) affirmed that leadership commitment and communication influence the efficiency of procurement staffs significantly. Leadership and management support plays a very important role in bringing forth enhanced organizational performance in procurement. Procurement entails the flow of goods, services and works across supply chains that involve many firms. The success of an organization's procurement is therefore highly dependent on the company's ability to support the procurement function and maintain good relations with other firms that form part of the supply chain network (Oyuke and Shale, 2014). So previous studies have shown that leadership has a positive impact on organizational performance as far as procurement is concerned. Top management plays a role to ensuring all members within the organization are committed to changes instituted within the procurement function. Therefore, any new procurement initiative cannot succeed in the absence of managerial support (Mose et al. 2013 ibid). This shows how influential top hierarchy could be on procurement decisions and its management. However, the direction of observed influence as cited in Daily Guide (2018 ibid) suggests the following hypothesis to be tested; H1: Top leaders have a significant negative influence on procurement management responsiveness. 


\subsection{Defining leadership and Leadership Role}

Books on the subject of leadership make it clear that the practical requirements of "leadership" are a matter of debate. Leadership may be variously described as being: the ability to focus the progress of a group; a personality trait; the ability to influence the behaviour of others; a form of specialized persuasion; a power relationship; an instrument to assist an organization in achieving its goals; a structural relationship within an organization; or some combination of the foregoing. Leadership is essentially about identifying the skills that will make anyone better at their job hence; leadership may be equated to doing a job right. For this reason, leadership training begins with giving people the basic skills require to assume responsibility, and to discharge whatever managerial authority may be entrusted to them in a way that - if not spectacular - is at least not manifestly incompetent or catastrophically bad. However, leadership goes beyond competence. Particularly, in the field of public administration, leadership requires generosity and compassion; fore-sight, knowledge and wisdom; strong decision making ability; and the ability to manage people effectively, as for instance by couching peak performance and building a strong team. Of particular importance in the procurement context is commitment to prudent management of resources.

The paper defines Leadership as the action of leading people towards achieving goals. In an organization, leaders do this by influencing employee behaviors in several ways. They set clear vision for the organization, motivates employees, guides employees through the work process and builds morale, as part of their roles (Kemunto and Ngugi, 2014; Walter \& George, 2017).

\subsection{Conceptual Framework}

Much influence can be exerted on employees during guidance in their regular work processes, from the authors view. Two major factors or roles come to play in leaders' quest to guiding staff on duty i.e. regular communication and commitment. Commitment for instance enables leaders to register their involvement either directly or indirectly in employees work process. Leadership is mainly consistent and reflects its commitment through an organization's philosophy, goals, policies, priorities, and executive behaviors. Again, any reform on procurement and procurement decision require a strong commitment from the senior management to adopt new organizational approach and to influence staffs to commit themselves to implement the new approach. On the other hand, Leaders that are capable of communicating with staff always succeed in implementing reform within the organization (Gilley et al., 2015). Zohar and Polachek (2014), Dobre (2013) and Morphitou (2017) confirm a significant relationship between leadership communication in organization and organizational performance. It has been found in many studies that leaders must listen effectively and communicate effectively to convince others to build consensus and trust (Beikoet al., 2016; Hopkins et al., 2015). By so doing the author is of a view that top leaders are able to interfer (if not dictate) procurement activities conscious or unconsciously to the procurement team.

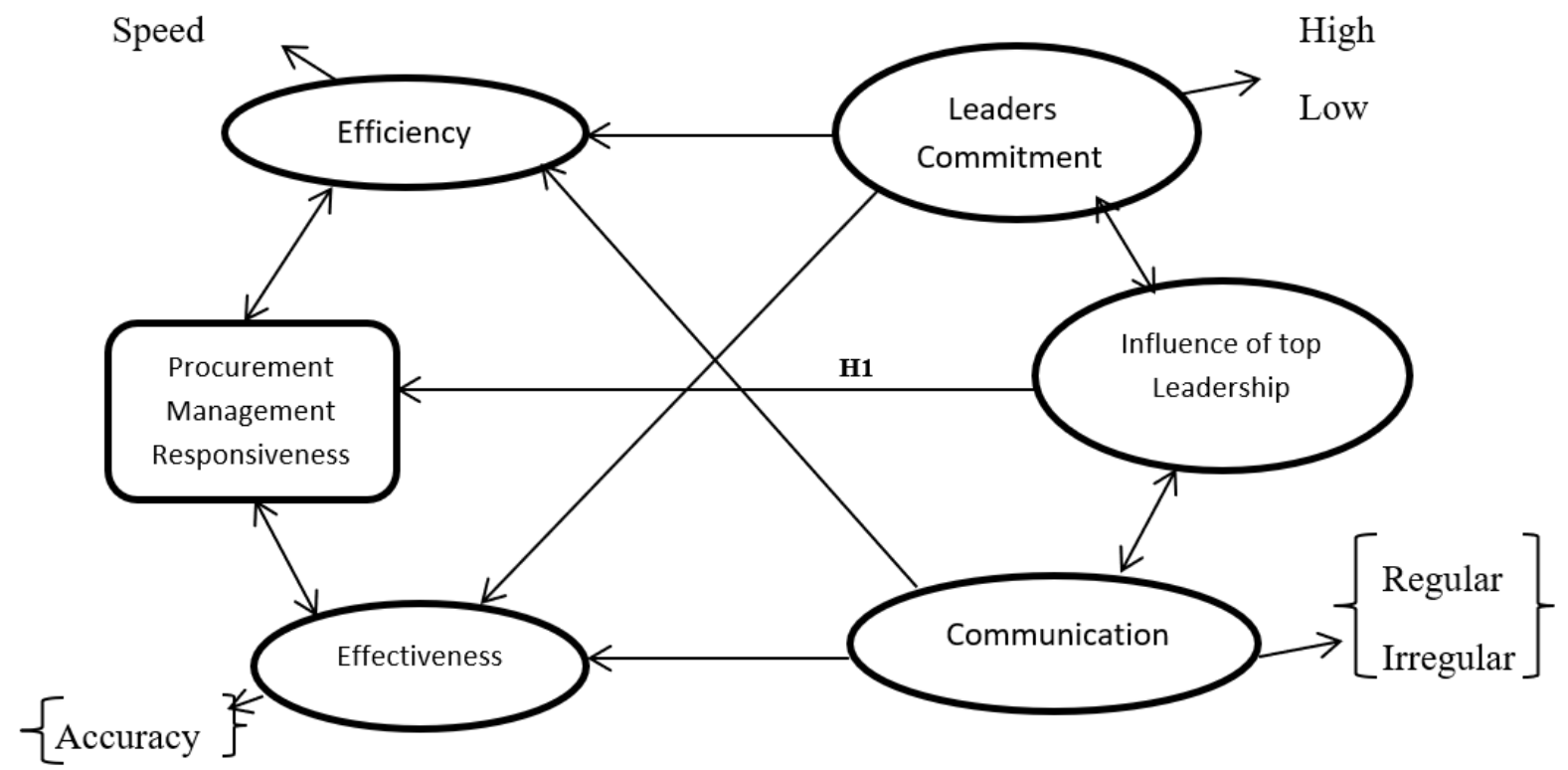

Figure1. Author's conceptual model (cited Beiko et al., 2016; Hopkins et al., 2015; Laffont et al, 1993)

Commitment and communication independently operationalize leaders' influences being measured as a continuous variable for the purpose of this study. Procurement on the other side technically involves finding and agreeing to terms, and acquiring goods, services, or works from an external source, often via a tendering or competitive bidding process (Laffont et al, 1993). The process of ensuring everything is in place for successful procurement is procurement management- applauded by its efficiency and effectiveness. For the purpose of this 
study the author perceives that in as much as top leadership duties touch various functional areas of a firm, their influence may mainly affect responsiveness [the efficiency (speed) or effectiveness (accuracy)] of the procurement process.

\subsection{Research Methodology}

Data for the study were collected through survey approach with structured questionnaires. Survey is considered to be the favored tool for data gathering amongst quantitative researchers (Fowler, 2009). This study utilized purposive-random sampling as a sampling technique. This technique allows every element in the chosen population to have equal probability of being chosen Sekaran (2003). It also has the least bias and offers the most generalizability (Sekaran, 2003). A total of 25 employees from procurement department of 5 of 8 technical universities in Ghana were randomly selected comprising of five staffs each. Correlation and Regression analysis were used to test the observed relationship between the independent variables and dependent variable (procurement management responsiveness). Likewise the predictor variable, the criterion variable was measured continuously using 5-point likert scale "strongly disagree to Strongly Agree".

\subsection{Result Presentation and Discussion}

Table 1: Descriptive Statistics

\begin{tabular}{c|c|c|c|c|c|c|c}
\hline & $\mathrm{N}$ & Mean & Std. Dev & \multicolumn{2}{|c|}{ Skewness } & \multicolumn{2}{c}{ Kurtosis } \\
\cline { 2 - 8 } Operational Constructs & Statistic & Statistic & Statistic & Statistic & Std. Error & Statistic & Std. Error \\
\hline Commitment & 25 & 3.50 & .505 & .000 & .337 & -2.085 & .662 \\
\hline Communication & 25 & 3.74 & 1.121 & -.634 & .337 & -.975 & .662 \\
\hline Top Leaders Influence & 25 & $\mathbf{4 . 0 0}$ & $\mathbf{. 7 2 8}$ & .000 & .337 & $\mathbf{- 1 . 0 6 3}$ & .662 \\
\hline Valid N (listwise) & 25 & & & & & & \\
\hline
\end{tabular}

The table above shows reliability of each constructs to determining the predictor variable. Leaders Commitment records a mean value of 3.50 , Std Dev $(\mathrm{SD})=0.51$ as communication had a mean statistic 3.74, $\mathrm{SD}=1.121$. Variances in both constructs seems insignificant and projects reliability of the criterion constructs confirmed at a mean response of $4.0, \mathrm{SD}=0.728$. More to it was symmetry in the data distribution spotted at a bench kurtosis $<3$ i.e. -1.063 hence giving way for parametric test (below) with the criterion variable.

Table 2: Correlation and Linear Regression Model Summary

\begin{tabular}{c|c|c|c|c|c|c|c|c}
\hline & & & \multicolumn{5}{|c}{ Change Statistics } \\
\cline { 5 - 8 } $\mathrm{R}$ & $\mathrm{R}^{2}$ & Adjusted $\mathrm{R}^{2}$ & Std. Error of the Estimate & $\mathrm{R}^{2}$ Change & F Change & $\mathrm{df1}$ & $\mathrm{df} 2$ & Sig. F Change \\
\hline $\mathbf{8 8 4}^{\mathbf{a}}$ & .782 &. $\mathbf{7 7 2}$ & .467 & .782 & 82.463 & 1 & 23 & $\mathbf{. 0 0 1}$ \\
\hline
\end{tabular}

a. Predictors:(Constant), Top Leadership Influence b. Dependent: PM responsiveness

From table 2, 77.2\% rate of responsiveness in procurement management (PM) can be explained by the linear relationship between the predictor and the criterion variable i.e. top leadership Influence and PM responsiveness. Pearson's Correlation co-efficient $\AA=0.884$ shows a very strong correlation between the variables which implies that top leadership heavily influences PM responsiveness at the selected technical Universities in Ghana. It can be said that just a few (22.8\%) PM activities goes through professionally (in various Universities) without top leadership influence - affirmed at a significant P-value $0.001<\alpha=0.05$. There is therefore enough statistical evidence to conclude that 'Top leaders have a significant negative influence on procurement management responsiveness' at the technical Universities.

\subsection{Discussion and Practical Implication of Result}

Scholars say leadership and management support play critical role in enhancing organizational performance (Kemunto and Ngugi, 2014 ibid). This was affirmed by Mose et al. (2013 ibid) when they opine that for any procurement initiative to be successful, it must enjoy full management support. Top management involvement is needed in procurement since their support for collaborative relationships between buyers and suppliers is essential to enhancing organizational performance' (Amemba et al., $2013 \mathrm{ibid}$ ). Direction of past studies suggests a positive influence of leaders' involvement on organizations procurement performance. Perhaps the storyline is different at technical universities. The present study finds the effort top leadership throws to enhancing procurement performance at Ghana technical Universities and it is very insignificant. It appears only $22.8 \%$ of procurement management responsiveness can be linked to good effort of top leaders at the various technical universities. To a very large extent (in about $77.2 \%$ cases) top leadership influences procurement decisions or management activities negatively giving procurement staffs a scanty room to exhibit professionalism in their work process. This partly affirms, Mohamad and Abdulrahman (2018) which revealed that leadership commitment and communication influence the efficiency of procurement staffs significantly albeit the scholars were silent on the kind of influence. Findings here is in sharp contrast with the cited works but buttresses Mohamad and Abdulrahman study with further light. Pragmatically top leadership at the technical universities is doing little to enhance procurement 
management at the institutions. They rather appear to be inducing the procurement processes of its professionalism maybe for their own parochial interest which needs further look. This has been confirmed with a significant negative influence established over procurement management responsiveness at the sampled universities'.

\subsection{Conclusion}

Previous studies have shown that leadership has a positive impact on organizational performance as far as procurement is concerned (e.g. Oyuke and Shale, 2014). Leadership and management support play a very important role in bringing forth enhanced organizational performance in procurement but the case of Ghana technical Universities appears something else with managing procurement, perhaps for self-interest. Findings of this study suggest that top leadership has a significant negative influence on procurement management responsiveness - which calls for attention. This influence is very strong as justified with Pearson's Correlation coefficient ${ }^{\circledR}=0.884$ at a P-value $=0.001$. Contrary to most previous studies, top leaders at Ghana technical Universities seem interfering procurement activities than enhancing it efficiency and effectiveness, and such interference may result in compromising professionalism in procurement management which will trigger consistent losses or misappropriations in the institutions. Maybe the case of Ho Technical University is a true evidence of this finding (see section 1.1) in effect; it is recommended that top leaders detach their interest going through procurement activities at the Technical Universities. This can be achieved through intensive moral and ethical training to top leaders of various institutions aside laying down some deterrents against such conducts. The Ghana Education Service and/or stakeholder authorities' can examine this recommendation for due consideration.

\section{References}

Minahan, T. A. (2004), “The Procurement Outsourcing Benchmark Report: Accelerating and Sustaining Total Cost Savings', March, electronic copy provided by Aberdeen Group.

Rudzki, R. A., Smock, A. D., Katzorke, M. \& Jr Stewart, S. (2005). "Supply Management: how are you Really Doing?" Supply Chain Management Review, December, Vol. 9, no. 9, pp. 10-15

Minahan, T. A. (2005). "Strategies for high-Performance Procurement," Supply Chain Management Review, September, pp. 46-54

Richter, G. (2001). “Centralize!” Purchasing, February 6, Vol. 12, no. 2, p. 37.

Warger, T. (2002). "E-Procurement gathers Speed: e-Procurement Brings the experience of Amazon.com to the Purchase of Academic Supplies and equipment - and it's about Time - Technology," accessed via http://findarticles.com/p/articles/mi_m01Sh/is_8_5/ai_95447847, on November 2, 2006

Nelson, D., Moody, E. P. \& Stegner, J. R. (2005). “The Ten Procurement Pitfalls," Supply Chain Management Review, April, pp. 38-45

Amayi, F. K. \& Ngugi, G. K. (2013). 'Determinants of public procurement performance in Kenya:Case Ministry of Environment, Water and Natural Resources', International Journal of Social Sciences and Entrepreneurship, 1 (5), pp. 647-667.

Amemba, C.S., Nyaboke, P.G., Osoro, A. \& Mburu, N. (2013). 'Challenges affecting public procurement performance process in Kenya',International Journal of Research in Management, 3(4), pp. 41-55.

Kalubanga, M. (2012). 'Sustainable Procurement: Concept, and Practical Implications for the Procurement Process', International Journal of Economics and Management Sciences, 1(7), pp. 01-07.

Oyuke, O.H \& Shale,N. (2014). 'Role of Strategic Procurement Practices on Organizational Performance; A Case Study of Kenya National Audit Office County’, EuropeanJournal of Business Management, 2 (1), pp. 336341.

Kemunto, D. \& Ngugi, K. (2014). Influence Of Strategic Buyer Supplier Alliance On Procurement Performance In Private Manufacturing Organizations A Case Of Glaxo Smithkline. European Journal of Business Management, 2 (1), pp. 336-341.

Walter P. K \& George O (2017), "Effect of leadership and management support to the procurement function on organizational performance" International Journal of Economics, Commerce and ManagementUnited KingdomVol. V, Issue 6, June2017 Licensed under Creative CommonPage 81 1http://ijecm.co.uk/ ISSN 2348 0386 